\title{
A Relação entre Religião e Estado: 0 jornal Do Dia e o golpe militar de 1964'
}

\author{
Douglas Hinterholz Cauduro²
}

\begin{abstract}
Resumo
O artigo faz uma avaliação sobre o posicionamento do jornal católico de Porto Alegre, Do Dia,_no golpe militar de 1964. De que maneira o impresso se utilizou da religião para garantir a adesão de seus leitores na proposta de retirada do presidente João Goulart do governo do Brasil. Para isso, o autor faz uma abordagem apontando a importância da religião na sociedade. Este trabalho vale-se da análise de conteúdo para desvendar a mensagem passada, na época, pelo jornal Do Dia à população da capital gaúcha. Ao final, pode-se notar uma campanha aberta pela deposição do presidente eleito, com o impresso se valendo do discurso religioso, e a tentativa do jornal de valorizar as Forças Armadas, através da ideologia cristã.
\end{abstract}

Palavras-chave: Religião. Estado. Ditadura militar. Jornalismo.

\begin{abstract}
The article makes an assessment of the position of the Catholic newspaper of Porto Alegre, Do Dia, in the military coup of 1964. In what way did the newspaper use religion to guarantee its readership in the proposal to withdraw President João Goulart from the government of Brazil. For this, the author makes an approach pointing out the importance of religion in society. This work is based on the content analysis to unveil the message given, at the time, by the newspaper Do Dia to the population of the capital of the state of Rio Grande do Sul. At the end, one can see a campaign opened by the deposition of the president-elect, with the newspaper using the religious discourse, and the newspaper's attempt to value the Armed Forces through Christian ideology.
\end{abstract}

Keywords: Religion. State. Military dictatorship. Journalism.

\section{Introdução}

Após o desenvolvimento e a concretização das sociedades baseadas em estado/nação, a religião passou a ser um pilar desse estilo de formação social. É inegável, historicamente, a relação próxima que os dois tiveram e ainda possuem. Normalmente, seus interesses são os mesmos, as ideias comungam e os discursos se alinham.

1 Artigo apresentado na ALCAR 2017.

2 Mestre em Comunicação Social pela PUCRS. douglascauduro@gmail.com 


\section{VOZES $_{\text {\&IÁLORO }}^{\mid}$}

Itajaí, v. 17, n. 02, jul./dez. 2018

Ter a religião como aliada na construção e fortalecimento do estado, passa a ser vital, dependendo do contexto histórico e social de cada sociedade. O Estado controla a sociedade através de suas leis e regras, enquanto que a religião tem (teria) o papel de assegurar, concretizar ou dignificar esse poder. "De fato, a Fé das grandes religiões dá segurança, alegria, liberação, a Verdade da Salvação garante a vitória da Certeza sobre a dúvida e dá Resposta à angústia diante do destino da morte” (MORIN, 2015, p.147).

Entretanto, com o aumento populacional e o crescimento das cidades, ficou mais difícil de encontrar um elo entre estado, religião e população. Porém, em virtude do distanciamento, a comunicação dessa trinca passou a ser conduzida através da mídia. Então, os dogmas, as doutrinas, a ideologia, o pensamento de uma religião pôde ser levado de casa em casa, pelo uso das plataformas midiáticas. "Uma grande Doutrina ou Teoria revela o Princípio que legifera e governa o mundo e constitui uma analogia abstrata/ideal do funcionamento do Universo" (MORIN, 2015, p.147).

Vendo esse caminho construído, pode-se notar que a divulgação das ideias religiosas saiu dos templos e afins, passando a circular em jornais, rádios, televisão e internet. "Mas como é essa relação? Como as religiões usam os meios de comunicação? O que eles dizem?" (MARTINO, 2003, p.9).

A religião e o estado tinham, principalmente, a condição de unir povos e garantir território. A soberania nacional acabava por vir através da força concentrada do Estado e da benção divina a partir de uma religião. Esse cruzamento deu resultado. Os países da Europa passaram a se desenvolver baseando-se neste dueto. Através de suas conquistas no plano global, conseguiram espalhar sua cultura e dominação pelos cantos do mundo:

\footnotetext{
Podemos adiantar que uma cultura constitui um corpo complexo de normas, símbolos, mitos e imagens que penetram o indivíduo em sua intimidade, estruturam os instintos, orientam as emoções. Esta penetração se efetua segundo trocas mentais de projeção e de identificação polarizada nos símbolos, mitos e imagens da cultura como nas personalidades míticas ou reais que encarnam os valores (ancestrais, os heróis, os deuses) (MORIN,1987, p.15).
}

A religião, mesmo como um ato de fé pessoal, acaba por levar uma criação de grupos que comungam através do mesmo ideal. $\mathrm{O}$ ato de ter fé, um ato pessoal, por sua vez, pode se espalhar, encontrando vários adeptos. Essa formação de grupos sociais, envolvidos pela crença, tem a possibilidade de ser vital na definição dos rumos da sociedade, seja ela descrente ou não. "Não pode existir um verdadeiro Estado, enquanto os homens permanecerem cristãos, ou seja, enquanto seguirem uma moral individual e perseguirem unicamente uma salvação individual” (LECLERCQ, 1972, p.22).

Colocando como exemplo central o Brasil, país majoritariamente católico, constatase a influência da religião na sociedade. A religiosidade interfere na maneira de ver o mundo. Então, mesmo que não haja nenhum partido religioso em disputa eleitoral, a 


\section{VOZES $_{\text {\&IÁLORO }}^{\mid}$}

Itajaí, v. 17, n. 02, jul./dez. 2018

diferenciação de ideologia pode levar essa massa religiosa a votar em algum candidato que tenha a mesma religião, ou escolher por um modo de governo que se assemelhe com a doutrina religiosa:

Ainda que a fé cristã, como concepção ideal de vida, especialmente na sua encarnação social e institucional, transcende indiscutivelmente toda a política - e nunca será demasiado insistir sobre isto - ninguém pode negar que a fé repercute ordinariamente e de muitos modos na política (LECLERCQ, 1972, p.63).

A sociedade interage através do gosto em comum. A ligação entre as pessoas, a formação do laço social, se dá na comunicação pela divisão de interesses similares. Compartilhar ideias, experiências e credos, são exemplos dessa tentativa de proximidade. A busca por fazer parte de algo, acompanha o homem em sua jornada na Terra. De acordo com Maffesoli, essas ligações humanas são formas de corporativismo:

Olhar transversal, ou alguma espécie de corporativismo, que constata que é a partir de um imaginário vivido em comum que se inauguram as histórias humanas. Mesmo que a etimologia esteja sujeita à caução, a religião (religare), a "re-liança" é uma maneira pertinente de compreender o laço social (MAFFESOLI, 2006, p.142).

Retomando as sociedades passadas e seus modos de viver em um estado/nação, aproveitando para traçar um paralelo com a sociedade atual, podemos notar uma clara ligação que não se desfez: o medo. A formação e a manutenção de um estado para assegurar e controlar as pessoas dentro de um território, a utilização da religião como um item máximo de comprovação moral, sem deixar de contar com a salvação após a morte. "Num mundo inseguro, a segurança é o nome do jogo. A segurança é o objetivo principal da competição e sua premiação suprema” (BAUMAN, 2010, p.92).

Através do medo do desconhecido, a Igreja Católica passou a atuar no ano de 1964. Foi no quarto ano da década de sessenta, em que a ditadura militar foi instalada no Brasil. Com receio do alastramento do comunismo na América Latina, em virtude da Guerra Fria $^{3}$, parte da sociedade, imprensa, políticos e Igreja Católica, passaram a vincular o nome de João Goulart ${ }^{4}$ ao comunismo. "O Brasil de Jango esteve sempre em ebulição. Cuba passara para o lado soviético. Os Estados Unidos, por meio de Aliança para o Progresso, procuravam domesticar e 'salvar' a América Latina” (SILVA, 2014, p. 30). Essa soma de forças, possibilitou o fortalecimento político e institucional das Forças Armadas na derrubada da democracia.

\footnotetext{
3 A Guerra Fria ficou assim conhecida pela falta de combate. Essa disputa se deu entre os EUA e a URSSA (União das Repúblicas Sócio Soviéticas) que buscavam aliados. Os americanos com o sistema capitalista e a União Soviética com o comunismo.

4 Conhecido também como Jango, João Goulart, eleito democraticamente em 1960, foi presidente do Brasil entre 1961 e 1964, até ser destituído do cargo pelas Forças Armadas, contando com apoio de alguns setores da sociedade e da mídia.
} 


\title{
VOZES $_{\text {\&IÁLORO }}^{\mid}$
}

Itajaí, v. 17, n. 02, jul./dez. 2018

\begin{abstract}
A Igreja Católica também representou papel ativo e importante durante todo o processo de tentativa de construção do consenso político em torno do projeto conservador e contra as reformas sociais, principalmente através do arcebispo de Porto Alegre, Dom Vicente Scherer, que, através de sua atividade pública, missas, jornais e seu programa rádio A voz do pastor, associava as reformas ao avanço do "comunismo materialista ateu", contrário à tradição católica e cristã do pacífico povo brasileiro. (PADRÓS e LAMEIRA Org. Padrós; Barbosa; Lopez; Fernandes, 2010, p. 43).
\end{abstract}

O pensamento cristão da época, se alinhou com a ideia propagada em virtude da Guerra Fria, do combate dos Estados Unidos contra o comunismo. Ressaltando, sempre, que o governo de João Goulart era visto como comunista, mesmo que em nenhum momento, o próprio presidente ou seus aliados tenham levantado essa bandeira.

\section{Metodologia de Pesquisa}

Para tentar entender da melhor maneira o envolvimento da religião católica utilizando um veículo impresso, na busca da construção de legitimação do golpe militar em 1964, o autor valeu-se da hipótese do agendamento e da análise de conteúdo.

Os exemplos utilizados pelo autor de editoriais, opinião e matérias do jornal católico Do Dia, foram todos pesquisados pelo próprio no Museu da Comunicação Hipólito da Costa, em Porto Alegre, Rio Grande do Sul, Brasil. Os recortes realizados pelo autor, buscaram contemplar a compreensão dos fatos narrados no ano de 1964. Para isso, o autor se vale da hipótese do agendamento:

Este princípio da função de agendamento desempenhada pelos media prediz que vamos encontrar uma acentuada relação positiva entre as ênfases da cobertura mediática e a importância assumida por esses assuntos para os indivíduos que compõem o público. Mais, este princípio é formulado em termos causais: a saliência acrescida de um assunto nos media provoca o aumento da importância desse assunto na consciência das pessoas. (TRAQUINA, 2000, p. 65).

Visando a análise do material pesquisado, dentro da concepção das metodologias, o autor utilizará a análise de conteúdo. Pois ela possibilita a avaliação sobre as mensagens dos veículos de comunicação. "A análise de conteúdo enriquece a tentativa exploratória, aumenta a propensão à descoberta” (BARDIN, 1977, p.30).

Um dos objetivos deste método é compreender o que há por trás do discurso do emissor. " $\mathrm{O}$ que se procura demonstrar a propósito das mensagens, ou pelo esclarecimento de elementos de significações susceptíveis de conduzir a uma descrição de mecanismos de que a priori não detínhamos a compreensão” (BARDIN, 1977, p.29). Para o autor, a compreensão do conteúdo publicado no jornal Do Dia trará luz a alguns pontos importantes na cobertura da mídia religiosa na época. 


\section{A religião como arma para adesão ao golpe militar:}

Na luta anticomunista de parte da sociedade brasileira, apoiada pela grande mídia e setores da sociedade, a Igreja Católica não ficou de fora. Seria, por parte da igreja, uma tentativa de salvação? Já que, se o suposto comunismo fosse implantado, as religiões não seriam permitidas no Brasil, assim como aconteceu na URSS?

"Revolução"; "volta da democracia”; "organização da pátria”, todos esses termos foram empregados pela mídia na saudação aos militares, criando uma agenda na população brasileira. "Para a terminologia do agendamento, os consumidores de notícias correspondem a membros sujeitos à influência dos media que ajudam a constituir a agenda pública” (TRAQUINA, 2000, p. 20). Porém, a religiosidade também foi destacada. O retorno da mentalidade cristã pelas Forças Armadas, se transformou em apelo popular pela aceitação do novo governo:

Quanto mais o círculo do poder se fechava, mais os representantes da ditadura insistiam em elaborar um suposto sistema de ideias e valores sobre uma democracia que reiterava, segundo eles, os desejos e a mentalidade cristã da sociedade no sentido de preservação do senso de dever e de autoridade (REZENDE, 2000, p.38).

Nessa perspectiva, a Igreja Católica passou, juntamente com outros setores da sociedade, na busca de legitimar o governo militar. Para a legitimação e legalização de um governo que nasce de um golpe, era necessário descontruir o adversário abatido e construir um perfil ideal do novo governo. Foi assim, justamente, que a religião Católica passou a agir. Buscava desqualificar o governo deposto e valorizar o governo recém instaurado:

A ditadura militar assentava a sua pretensão de legitimidade sobre quais elementos? As bases em que ele estabelecia o seu empenho para obter reconhecimento dos diversos segmentos sociais para os seus atos, medidas, ações e desígnios eram eminentemente autocráticas (REZENDE, 2000, p.29 e 30).

Em 1964, a Igreja Católica se utilizou da ideologia religiosa para fazer campanha contra as propostas de João Goulart, além de intitulá-las como comunistas. Então, em nome da "democracia", essa combinação de instituições sociais acabou por derrotar a democracia no país. "A mídia, em 1964, enquanto falava sem parar de democracia e de ordem constitucional, preparava o lombo dos brasileiros para os golpes que eles sofreriam por duas décadas e meia” (SILVA, 2014, p. 8).

Através do golpe na Constituição que afastou João Goulart e tirou a democracia do Brasil, o brasileiro pôde perceber a força da religião e quanto ela pode interferir no Estado. "A distinção entre política e religião foi historicamente estabelecida pelo cristianismo mais como uma meta do que como um dado de fato: o princípio contém 


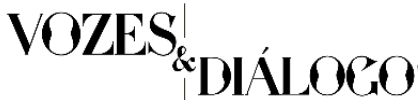

Itajaí, v. 17, n. 02, jul./dez. 2018

uma chamada a tornar efetiva e concreta a realidade nela anunciada” (LECLERCQ, 1972, p.18).

\section{O jornal Do Dia e a legitimação do golpe militar}

Em 1964, a capital do Rio Grande do Sul, Porto Alegre, era sede do jornal Do Dia. O católico impresso circulava pelas ruas da Capital gaúcha, apontando e contextualizando o noticiário diário através da visão católica. Seguindo o pensamento da Igreja, na época, o jornal Do Dia apostou no reestabelecimento da democracia com a remoção de João Goulart do poder e na remoção das políticas com cunho sociais, tidas como propagação do comunismo. "Ao oferecer ao fiel a 'palavra', a boa 'interpretação' dos fenômenos, a instituição religiosa facilita a inteligibilidade da vida social” (MARTINO, 2003, p.35).

A população recebeu do jornal Do Dia, opiniões conservadoras e desfavoráveis ao governo de João Goulart. A ideologia religiosa, combinada com a divulgação midiática, pedindo interferência no governo, ajudou a causar um agendamento na sociedade, que passou a ver o governo de Jango como "anticristão", “comunista” e "antidemocrático".

A religião ajuda a definir ações sociais. Se apegando nisto, o jornal Do Dia_apostou na colaboração da sociedade cristã para auxiliar na remodelação no tipo de governo do Brasil. Para comemorar a vitória no campo político, o jornal religioso lembrou de Deus e não se preocupou com as mortes que já aconteciam no dia da deposição de João Goulart:

[...] Em última hora um povo se levantou aos 31 de março e sacudiu as correntes férreas do comunismo ateu e desumano, que traidores lhe queriam impor de maneira super-humana e bem cristã os brasileiros resolveram, com o auxílio de Deus e sua mãe em 2 dias e meio com meia dúzia de mortes, o que a outros como os espanhóis tem custado anos de guerra civil e milhões de mortos. Longe fanfarrices e de vinganças, o povo mete, calma e firmemente, mãos à obra da reconstrução da SUA PÁTRIA! (JORNAL DO DIA, 07 de maio 1964).

O Jornal Do Dia_manteve o discurso de tachar o governo de comunista, chegando a chamá-lo de desumano. Mas, para o jornal, não era desumano a morte de brasileiros meia dúzia de mortes segundo a publicação - não eram importantes para serem lamentadas e se tornarem vítimas de uma tragédia. A reconstrução da pátria vinha em nome de Deus e sua mãe. Mais uma vez, agora através das páginas de um jornal, a religião era utilizada como arma política. Religião e Estado se encontravam novamente no golpe militar brasileiro.

A religião teve papel importante na desconstrução do governo João Goulart. A teoria do governo comunista, por tentar atender às classes baixas, passou a ser propagada em grande escala pelos veículos midiáticos religiosos e pelos não religiosos também. " Assim, enquanto referência a este mundo social como um todo, a religião permanece uma referência transcendente" (MARTINO, 2003, p.35). A visão católica, totalmente contrária 


\section{VOZES $_{\text {\&IÁLORO }}^{\mid}$}

Itajaí, v. 17, n. 02, jul./dez. 2018

ao comunismo, se engajou também, nesse pensamento de desestabilização do presidente Goulart por parte de suas políticas de atendimentos aos menos favorecidos.

O jornal Do Dia_via o golpe militar como revolução. O reencontro nacional com a democracia. Mas não conseguia enxergar, ainda, uma melhora na situação no estado do Rio Grande do Sul:

Líderes políticos gaúchos pediram ontem ao Deputado Armando Falcão que transmitisse ao Presidente Castello Branco e seu ministério, bem como aos altos comandos da Revolução, a sua preocupação com a situação no Rio Grande do Sul, onde, em sua opinião as coisas continuam quase como antes do movimento de 31 de março. (JORNAL DO DIA, 10 de maio de 1964, p. 2).

O Rio Grande do Sul preocupava os apoiadores do golpe. Foi neste Estado em que João Goulart, ao lado de seu cunhado, Leonel Brizola, pode defender sua posse em 1961. A Campanha da Legalidade, como ficou conhecida, teve sua sede em Porto Alegre, capital do Rio Grande do Sul:

[...] o governador do Estado do Rio Grande do Sul, Leonel Brizola, casado com uma irmã de Jango, espírito de fogo, impulsivo, impetuoso, ousado, no auge de sua potência combativa e do seu desejo de confronto, comandou a resistência através de uma rede de emissoras de rádio Cadeia da Legalidade, tendo a Rádio Guaíba à frente - que culminara na posse de Goulart em 7 de setembro de 1961. (SILVA, 2014, p.19).

Mas não era somente de notícias e editoriais voltados ao apoio à ditadura militar que o jornal Do Dia apresentava sua ideologia. O impresso abriu espaço para o coronel Yeddo Blauth explicar como funcionava o "comunismo" no Brasil, e de que maneira essa teoria política/econômica/social havia conquistado espaço em território brasileiro:

Evidente que só um comunista de cúpula sabe tudo sobre a técnica de infiltração vermelha, mas qualquer interessado no assunto pelo estudo e observação consegue uma boa noção da técnica comunista de infiltração, que é eficiente, e como quase todas as coisas eficientes, também é simples. Começa baseando-se em que há pessoas fanáticas e intolerantes que acreditam sinceramente que o regime ateu e de cabresto é o melhor para a humanidade. (JORNAL DO DIA, 10 de maio de 1964).

Até mesmo na avaliação do coronel Blauth, a questão religiosa vem à tona. $\mathrm{O}$ comunismo, tão batido e criticado em todos os veículos favoráveis ao golpe, também era mal visto pelo católico Do Dia. Porém, o ateísmo do governo Goulart, segundo a publicação, também se transforma em motivo suficiente para derrubada de um presidente. "A despeito da diferença de graus de adesão à instituição, a religião segue sendo importante instrumento produtor e divulgador de uma ideologia de classe" (MARTINO, 2003, p.40).

Seguindo a tendência de explicar como as construções devem funcionar, o jornal Do Dia_não perdeu tempo. "O que se tem é a busca, por parte das instituições, de legitimação perante a sociedade, a fim de divulgar suas ideologias” (MARTINO, 2003, 


\section{VOZES $_{\text {\&IÁLORO }}^{\mid}$}

Itajaí, v. 17, n. 02, jul./dez. 2018

p.45). Logo, a publicação resolveu explicar o que era, afinal, democracia e liberdade. Apostando, abertamente, que o novo presidente brasileiro seria um pacificador:

A democracia é isto: os operários trabalhando ordeiramente nas fábricas e nas oficinas, longe das ingerências dos profissionais da baderna, que os estimam não como homens, mas como massa. (...). Em seu discurso de posse nosso valoroso presidente pronunciou as palavras que há muito desejávamos ouvir. Falou como um verdadeiro apóstolo da dignidade, da honradez, como um mensageiro da paz, escravo do dever, que na idade de ensarilhar as armas volta ao campo de batalhas, assume as rédeas de um poder que nunca ambicionou, para reconstruir e libertar a sua pátria. (JORNAL DO DIA, 26 de abril de 1964).

Para o jornal Do Dia, a democracia não passava de um estágio de cumprimento de ordem. Instituições, como os sindicatos, serviriam apenas para a baderna e para transformar o homem em massa. A organização de uma classe trabalhadora não era bem quista pela opinião do impresso. Porém, o general que virou presidente, Humberto de Alencar Castelo Branco, era digno, honroso, pacificador, um homem que cumpria seu dever, não possuía ambição, apenas estava fazendo um trabalho de colocar o Brasil nos trilhos da liberdade e da honradez cristã.

A mídia religiosa, aliando dois discursos legitimantes, o religioso e o da mídia - um por sua condição de dogma revelado, outro por sua pretensão de objetividade -, procura reforçar esta ou aquela posição, com cuidado que tais questões possam ter aparência e relevância doutrinária que justifique sua presença em um veículo religioso. (MARTINO, 2003, p.149).

\section{Considerações finais}

A proposta deste trabalho era de apresentar a relação entre Estado e religião. De que maneira os governos tinham sido influenciados pela religião, ou, como a religião acabava influenciando a população na escolha por um governo. Claro que nesse segundo momento, mais um fator foi levantado: a mídia. A ligação entre esses três elementos acabou sendo focalizada no caso do jornal Do Dia, em 1964, quando o impresso apoiou o golpe militar.

Ao longo do trabalho, o autor buscou levantar abordagens que são utilizadas pela religião, utilizando a mídia e refletindo na forma de governo. De maneira que a Igreja Católica passou a apresentar o que não gostava do governo deposto e o que admirava do novo governo. A criação de uma agenda dos principais pontos negativos do governo Goulart foi criada. Assim como foi construído, uma série de argumentos na tentativa de convencimento e legalização do governo militar.

Para isso, não se está dando poderes inexistentes à religião, apenas retomando e reafirmando a importância que ela continua a ter. A construção social 


\title{
VOZES $_{\text {\&IÁLORO }}^{\mid}$
}

Itajaí, v. 17, n. 02, jul./dez. 2018

também passa pela crença de cada um. Não se pode subestimar algo que é milenar, lhe acompanha pela vida e promete estar contigo na hora da morte e após:

\begin{abstract}
A questão principal é de ordem lógica: como é possível algo que está desaparecendo ter tanta força? Se a religião pouco importa na vida cotidiana, o que fazem milhares de fiéis nos templos das mais diversas seitas religiosas? Como se formam "bancas evangélicas" nas câmaras legislativas, interferindo ativamente no cenário político, costurando alianças e indicando candidatos? (MARTINO, 2003, p.47).
\end{abstract}

Pode-se notar, inclusive, a expansão no raio de atividade das religiões. A religião passou a ser dona de grupos de comunicação. Jornais, televisões e rádios, assim como estão nas mãos das famílias de políticos, essas mídias também possuem no seu âmago, uma crença religiosa. Quer se acredite ou não, a religião possui mecanismo para atingir à distância seu público e novos fiéis. Sem sair de casa, o leitor/telespectador/ouvinte acaba por ser conectado com o pensamento religioso.

Através dos exemplos demonstrados do jornal Do Dia, identifica-se a tendência do impresso em se manifestar com o pensamento católico, nos assuntos políticos e sociais. $\mathrm{O}$ discurso do jornal optou por desconstruir o presidente João Goulart e suas medidas, não se importando, inclusive, com algumas mortes que aconteceram em virtude da tomada do poder pelos militares. Existiu ainda, a incoerência no discurso. Um jornal que dizia que a democracia estava sendo reestabelecida, não era capaz de aceitar o ateísmo. Julgava em razão disso.

Pelo que já observamos através da história e neste caso específico no Brasil, no ano de 1964, pode-se dizer que a religião ainda possui sua influência nos meios sociais e que ela, dotava de novas ferramentas, poderá aumentar seu poder de doutrinação.

\section{Referências}

BARDIN, Laurence. Análise de Conteúdo. Lisboa: 70, 1977.

DUARTE, Jorge; BARROS, Antônio. Métodos e técnicas de pesquisa em comunicação. São Paulo: Atlas, 2011.

LECLERCQ, Bertrand J. de. Religião e política. Porto: Perpétuo Socorro, 1972.

LOMÉNIE, Beau de. A igreja e o estado: um problema permanente. São Paulo: Flamboyant, 1958)

MARTINO, Luís Mauro Sá. Mídia e poder simbólico: sobre comunicação e campo religioso. São Paulo: Paulus, 2003.

MORIN, Edgar. O método 3: conhecimento do conhecimento. Porto Alegre: Sulina, 2015.

, Edgar. Culturas de massa no século XX. São Paulo: Forense, 1987. 


\section{VOZES $_{\& \text { DIÁLORO }}^{\downarrow}$}

Itajaí, v. 17, n. 02, jul./dez. 2018

PADRÓS, Enrique Serra; BARBOSA, Vânia M.; LOPEZ, Vanessa Albertinence; FERNANDES, FERNANDES, Ananda Simões (org). A ditadura de segurança nacional no Rio Grande do Sul (1964-1985): História e memória. Repressão e Resistência nos "Anos de Chumbo". Porto Alegre: Corag, 2010.

GIL, Antônio Carlos. Métodos e técnicas de pesquisa em comunicação. São Paulo: Atlas, 2006.

LARANJEIRA, Álvaro Nunes. A mídia e o regime militar. Porto Alegre: Sulina, 2014.

REZENDE, Maria José de. A ditadura militar no Brasil: repressão e pretensão de legitimidade 1964-1984. Londrina: UEL, 2001.

SILVA, Juremir Machado da. 1964: Golpe midiático-civil-militar. Porto Alegre: Sulina, 2014.

TRAQUINA, Nelson. O Poder do Jornalismo: Análise e textos da teoria do agendamento. Coimbra: Minerva, 2000.

WOLF, Mauro. Teorias da Comunicação: Mass Media: Contextos e paradigmas; Novas tendências; Efeitos a longo prazo; newsmaking. Lisboa: Presença, 1999. 